\title{
The Technology Roadmapping Method and its Usage in Chemistry
}

\author{
Aline Marta Vasconcelos Loureiro', Suzana Borschiver², Paulo Luiz de Andrade Coutinho
}

\begin{abstract}
Technology roadmapping is a widely used technique in the industry for the development of long term planning strategies, making it possible to align market, product and technology over time. This article offers a brief review of this tool, covering the definitions of the terms technology roadmap and technology roadmapping, the types and formats of roadmaps, the structure of roadmaps, the processes of operation/adaptation of roadmapping, challenges and the key successful factors in implementing the roadmapping and its usage. Finally, an overview of public domain roadmaps is given, with special highlight to the ones related to Chemistry.
\end{abstract}

Key words: technology roadmapping; technology roadmap; roadmaps in Chemistry.

\footnotetext{
I Brazilian Institute of Industrial Property (INPI-Br) Rua Mayrink Veiga, no 9 / 19 o andar - Centro - CEP 20090-050 - Rio de Janeiro, Brazil. Phone: +55 (2I) 21393573. Department of Organic Process, School of Chemistry, Federal University of Rio de Janeiro (UFRJ) Centro de Tecnologia, Bloco E - $2^{\circ}$ andar - Sala E-204 - Cidade Universitária - CEP: 21949-900 - Rio de Janeiro/RJ - Brazil. Email: alinemartaufri@hotmail.com

2 Department of Organic Process, School of Chemistry, Federal University of Rio de Janeiro (UFRJ) Centro de Tecnologia, Bloco E - $2^{\circ}$ andar - Sala E-204 - Cidade Universitária - CEP: $21949-900$ - Rio de Janeiro/RJ - Brazil. Email: suzana@eq.ufri.br ${ }^{3}$ Braskem S.A. Avenida das Nações Unidas, 850I / 25a andar - Pinheiros - CEP: 05425-070 - São Paulo/SP - Brazil. Email: paulo.coutinho@braskem.com.br
} 


\section{Introduction}

Technology roadmaps are becoming popular as tools to manage the future of technology. They have been developed to different kinds of publics and matters, being characterized for forecasting what is possible or likely to happen, and also for planning its follow up. (Kappel, 200I).

Technology roadmaps have become prominent because they link technologies, products and markets at high levels of abstraction, with enough potential to become infrastructure to innovation (Rinne, 2004). Technology roadmaps produce multidimensional views of an organization to identify the most interesting opportunities in which to invest time, money and resources before the decisions are made.

This way, the technology roadmapping method assists structuring the planning process, allowing the visualization of gaps in the strategic planning, by aligning future goals and the activities present in the organization. This allows to identify and prioritize a sustainable competitive advantage and to correctly allocate the organization's technological and human resources.

The roots of technology roadmapping can be credited to the North American automobile industry. However, the first organizations to successfully implement them were the great technology corporations Corning and Motorola, in the late 70's, early 80's (Drummond, 2005). The roadmap to the semiconductors is considered the most famous among the industrial roadmaps.

Robert Phaal (2008) identified nearly I 300 public domain roadmaps found on the internet, covering the most diverse areas of science, technology and industry, grouping them in areas of study. Even though there is a specific classification for Chemistry, the number of roadmaps of issues related to this science can increase, if we consider the existing interface with Chemistry in roadmaps classified in other areas, as it will be verified later in this work.

\section{Definitions to Roadmap and Roadmapping}

Literature has presented the term "technology roadmap" in different ways, such as "technology roadmap", "technology road map" or simply "roadmap", or also as its acronym "TRM” (Lee; Park, 2005).
In general, the expression "road map" refers to a layout of ways or routes that exist or might exist in a place in order to help travelers plan a trip and reach a specific destination. This definition helps to understand that the technology roadmapping method provides a graphical representation of existing technologies, products and markets (nowadays) and ones to be built (in the future), and how they evolve, helping the leaders (travelers) of an organization to plan and align the development strategies with business goals (destination). (Mattos Neto, 2005).

According to Kappel (200I), indicating a definition to roadmapping has become a challenging task, given the popularity boom of the term, where any prospective document is named roadmap. A basic difference is that roadmapping (the process) can be done with different goals, whereas the roadmaps (the documents generated in this process) may refer to different aspects of a planning problem.

To Phaal et al. (2004), the technology roadmapping process represents a powerful technique to support technological management and planning, especially to explore and communicate dynamic interactions between resources, organizational goals and environment changes.

To Garcia and Bray (1997), the technology roadmapping process provides a way to develop, organize and present information about critical requirements and desirable performance of objectives that must be achieved at the planned time.

To Petrick and Echols (2004), technology roadmapping consists of a tool that enables the organizations to make decisions more consciously, preventing waste of time and valuable resources, helps to reduce the risk associated to uncertainties, and as a result, increases the number of right decisions.

As to roadmapping, the term roadmap is widely used, generally describing a plan for the future, but varying greatly in their goals and styles. Muller (2005) describes that roadmap is a prospection integrating all of the relevant aspects of the business (market, products, technology, process, and people) considering time. Kappel (200l) reports that what differs roadmaps from other strategic documents in a corporation is nothing but the explicit revelation of the time domain for each element in it. 
Throughout this work, the definition used to the term technology roadmapping is of a flexible method in which the main goal is to assist strategic planning in market development, product and technology in an integrated way, over time (Albright; Kappel, 2003; Kappel, 200 I; Phaal et al., 200I, 2004), whereas the term technology roadmap consists of a document generated by the process.

\section{Kinds and Formats of Roadmaps}

A valuable characteristic of roadmaps is its concise presentation. The visual nature has specially assisted the structured and constructive discussion of technological prospection processes. In order to better understand and categorize the variety of roadmaps found in literature, some authors use criteria related to its kinds and formats.

Roadmaps can have many formats, but the most common is the one presented in Figure I. Generically, roadmap is a graphical representation based on time, containing a number of layers that typically include technological and commercial perspectives (Phaal et al., 200I). To Kappel (200I), roadmaps must have the key elements market, product and technology, over time and associated to one part of the business.

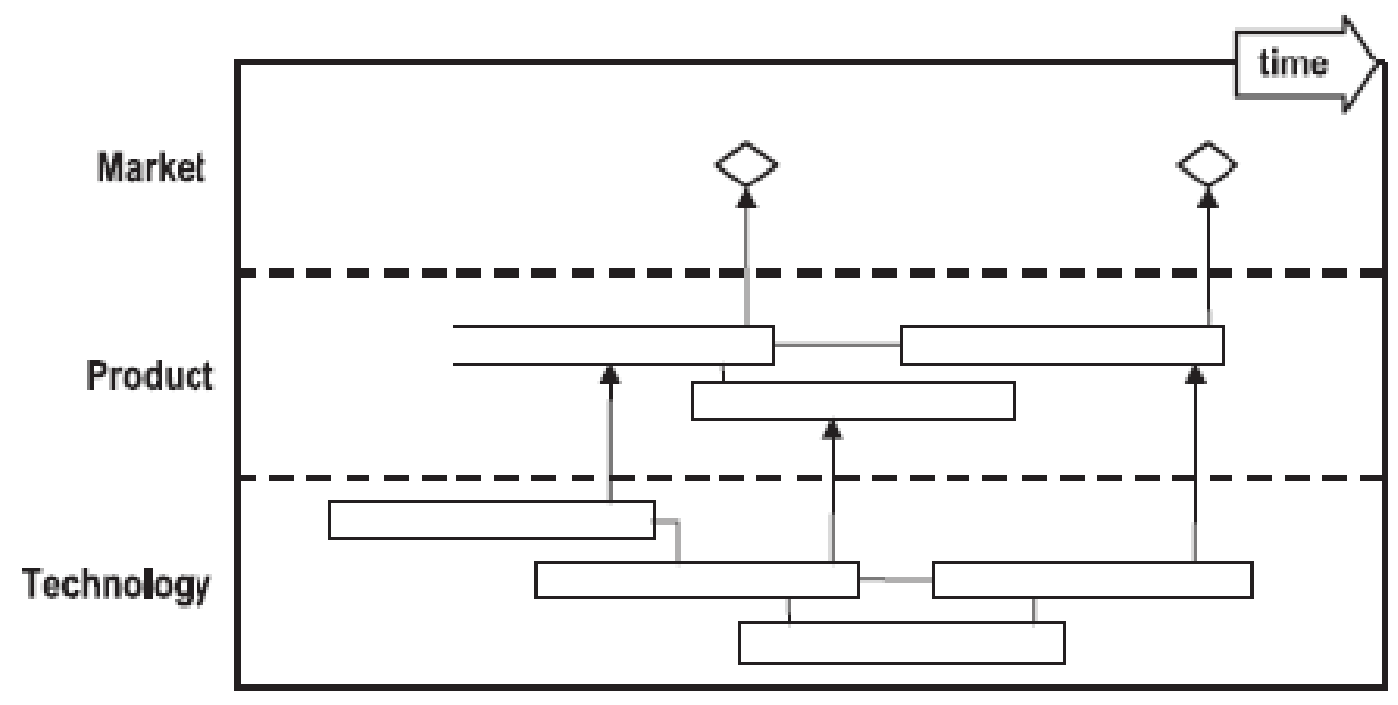

Figure I. Schematic technology roadmap showing how technology can be aligned to the development of products and services, business strategies and market opportunities. Data from PHAAL, FARRUKH, PROBERT (2004).

Studies suggest that roadmap can be represented in two ways: industrial or corporative (Kappel, 200I; Phaal et al., 2004). Some organizations perform the technology roadmapping internally, as an aspect of its technological planning (corporative technology roadmap). However, at industrial level, technology roadmapping involves multiple organizations, individually or in consortium (industrial technology roadmap).

One of the classifications related to the types of roadmaps is the one described by Garcia and Bray (1997) that defines three kinds of roadmaps. The technology roadmap of product is driven by the needs of product and/or process. The technology roadmap is directed to a specific technology and focuses on the forecast of development and commercialization of a new or emerging technology, the company's competitive advantage related to this technology and how this emerging technology and the company's position will develop. The technology roadmap directed to a specific subject intends to identify problems and its consequences to the strategic planning and budget.

Phaal et al. (2004) examined a group of nearly forty technology roadmaps and organized them in sixteen areas of study. From these 16 areas of study, eight relate to the purposes (planning of: product, service/capacity, strategy, long term, knowledge, program, process and integration) and eight relate to the formats (multiple layers, bars, 
tables, graphs, pictures, flowchart, single layer and text) of roadmaps.

\section{Structure of Roadmaps}

Albright (2007) reports that roadmaps show the objective to be achieved in the future and answer the set of questions "why-what-how-when" in order to develop the action plan and achieve such goal. The first part defines the scope of the roadmap, the set of goals, and the strategy to achieve them - the roadmap's "why". The definition and the strategy of the roadmap generally include market and competitiveness assessments as well as desirable applications. The second part defines the direction or the plans - the roadmap's "what". The direction includes challenges, architecture, the way solution evolves and the measured performance to achieve the goal. The third part describes the evolution of the technologies that will be used to achieve that goal - the roadmap's "how". Technology roadmaps define the technologies that will be used to implement each part of the architecture. The forth part defines the action plan and the risks - the roadmap's "to-do's". The action plan identifies key actions of development, necessary resources, risks and technological investment strategy. All parts are placed over time - the roadmap's "when".

Still related to the roadmap's structure, Phaal et al. (2004) proposed that the construction can follow two different ways: the market and pull and the technology push approach. This way, in the organizations that are deeply in contact with the final consumer, the roadmap will probably be directed by the client's needs, whereas the tecnology push approach will be used to products that result from scientific development.

\section{Roadmapping Operation / Adaptation Process}

Each technology roadmapping application tends to be different depending on the following factors: the needs and the organization's goals; the business structure, the systems, processes, procedures and tools used, as well as the information present in the organization; the area of application; and the available resources.

To Muller (2005), an efficient way to create or update the roadmap consists in fully concentrating a few days on this goal. A good preparation of the people involved is essential to make these days productive. This way, the first days must be dedicated to group preparation, focusing the roadmap's sections related to market, product and technology, making it necessary some time to "digest" the material presented in the discussions. When executing the roadmap the most important stage consists in selecting the most relevant topics.

In some cases a pilot is suggested in order to explore the way the technology roadmapping functions, identify potential elements of adaptation, "sell" the method, generate partial results to achieve the commitment of the board of directors and the resources necessary to implement and identify the gaps in the corporation's knowledge (Mattos Neto, 2005; Phaal et al., 200I; 2004).

Below, the three main processes of application of producttechnology roadmapping available in literature will be presented.

The procedure for the application of the technology roadmapping, called T-Plan, is the result of three years of applied search, in which more than 20 roadmaps were developed in co-operation with many different kinds of industries in many different areas by Phaal et al. (200I, 2004). The T-Plan is a practical guide to a fast application ("fast start") of the technology roadmapping that has as its goal to assist the main challenge faced by organizations: generating the first roadmap. With this aim, the guide is focused on the standard application of technology roadmapping to great industries. The T-Plan is structured through seminars, covering from the planning to the implementation of its results. The T-Plan process includes four workshops - the three first focusing the three first layers of the roadmap (market/business, product/service and technology) - and the last workshop jointing the layers according to the variable time to the construction of a graph. All workshops happen in the presence of a facilitator.

The application procedure of the technology roadmapping described by Albright and Kappel (2003) was the result of various years of experience in Lucent Technologies (a North American telecommunications company founded in 1996). The technology roadmapping must be organized in four seminars: market, product, technology and creation of the action plan and risk analysis. The market seminar defines the segments of the market that the organization wishes to achieve, in terms of size, growth, consumer's needs, analysis of main competitors, competitive strategies, 
participation in the key-segments, qualities and weak points. In the product seminar, the characteristics evaluated by the consumer at the time of purchase are translated into terms of technical characteristics of products in a quantitative way. The technology seminar can be considered the key element for the roadmapping, because a lot of information is condensed there. The last seminar has as its objective, to summarize the results and to create an action plan of a map with the risks that must be monitored. The product technology roadmap created must explicit the links between the most important questions to consumers and the key technological areas to guide the progress of products - and the company itself in these questions. For this reason, the technologies presented in the roadmap, show how business and product strategies will be implemented in technological terms.

The technology roadmapping developed by Garcia and Bray (1997) involves three stages: preliminary activities, roadmap development and updating activities. In the first stage the ones responsible for making the decisions must notice the problem that the technology roadmapping might help them solve. The stage for the development of the technology roadmapping involves seven steps that are similar to the corporative and industrial levels; however the operation of the industrial roadmap requires more resources and time. In the last stage, a group of people larger than the small group involved in the development of the technology roadmapping criticizes, validates, and accepts the described roadmapping. The authors state that the difficulty in keeping the roadmaps "alive" is generally the greatest hindrance to its effective use.

By means of a search of recently published articles, many different operation processes of technology roadmap with different uses were found, some are highlighted below.

Daim and Oliver (2008) published an article describing the implementation of technology roadmapping in the area of energy services by means of case study of a governmental energy transmission agency in the northeast of the U.S. Four areas to the development of roadmaps were identified: renewable energy, transmission, energy efficiency and hydroelectric energy. The authors drafted four implementation steps to the roadmapping process in this sector: establishment of organization's goals, strategies and researches of the area; development and implementation of a training program shown as

ISSN: 07I8-2724. (http://www.jotmi.org)

Journal of Technology Management \& Innovation @ Universidad Alberto Hurtado, Facultad de Economía y Negocios roadmapping is an effective tool; data collection and the creation of roadmaps in each department (process similar to T-Plan); and review and constant ratification of organizational roadmaps.

Lee, Mogi and Kim (2009) elaborated an energy technology roadmap (ETRM) in Korea for the next 10 years (from 2006 to 2015) moved by the lack of this kind of roadmap, the need of policies formulators' to know the direction of energy technology development and for the fact that the Korean economy is easily affected by the prices of oil. The methodology of execution of the roadmapping was divided in three stages: listing the energy technologies developed in Korea; analyzing various technologies based on factors like potential market, patents and copyrights; assessing the current stage of R\&D in energy utilizing the SWOT analysis; and the construction of ETRM through the selection of the three greatest technological areas.

Li (2009) used the case study method based on qualitative and quantitative data in order to explain how Cisco's business ecosystem has been successfully used in merger and acquisitions strategies to corporative growth. The technological roadmap from Cisco's business ecosystems was based on keywords taken from U.S. patents, between 1993 and 2005, and its frequency relations were statistically analyzed to create the roadmap.

Suh and Park (2009) proposed a technology roadmap to the service industry using a patent map (three-dimensional visualization method and analysis tools based on keywords), which contributes to evaluate the emerging technologies related to services. The roadmap's construction was summarized in the following steps: building the patent map with keywords from the service technologies and the list of services offered, by means of co-operation with experts from the service industry; evaluating the priorities of the technologies attributing values to the ones in the patent map; and creating the technology roadmap using the most interesting technologies.

Lee and collaborators (2009) also suggested the patent analysis to make a roadmapping driven by technology the process starts from the capacity analysis to the technological planning and ends with the business opportunity analysis to market planning. They proposed the use of patent data as a parameter close to the 
technological capacity, because patents are considered a great source of technical and commercial knowledge about technical progress and innovative activities. The roadmapping objectivity and reliability, based on the experts opinion, can be increased through the integration of patent analysis in the raodmapping process, once they help to extract more strategic information to assist the decision making process.

Hinkebein and Price (2005) presented a roadmap to desalination and water purification, where the main objective is to identify areas of research that may result in cheaper and revolutionary technologies to desalination and water purification and the secondary goal is to identify researches that may solve the current technologies deficiencies. The structure proposed to the development of this roadmap includes five steps: the identification of needs (assessment of the challenges in various geographical regions in the U.S.); creation of critical objectives to each need; creation of metrics (quantification) to each objective; identification of technological areas that offer the best chances to find future needs, critical objectives and metrics; identification of research areas and technological advances that could achieve the objectives.

Kim and others (2009) developed a technology roadmap to the construction industry, in which the needs for future technologies of construction were organized through efforts of inter-discipline researches. The construction process of the roadmap was structured on the assessment of environmental conditions: socioeconomic factors (globalization, environmental and energetic questions, for example), technological tendencies (by means of scientific articles and patent analyses) and identification of market's needs (through research based on questionnaires and experts opinion).

Hence, according to Phaal et al. (2004), in order to have an efficient application of the roadmapping it's crucial to adapt it to the peculiarities of each organization.

\section{Challenges and Key Successful Factors for Implementing the Roadmapping}

According to Phaal et al. (200I), the organizations normally face two challenging issues applying the technology roadmapping:
I. How to start the process for the first time?

\section{How to keep it active?}

The first question naturally occurs because the technology roadmapping has to be adapted to the organization's reality and need, which is not always trivial. The second doubt refers to the capacity to keep the process "alive" in the organization, what is made possible through periodic reviews of the roadmap, in a way to extend its extension into other areas of business and integrating with the generated roadmaps.

When executing the roadmap the most important stage consists in the selection of the most relevant issues (Muller, 2005). The selection of the best technology among the available options should consider the evaluation of notions of cost, benefits and risk, as well as involve the choice of the most adequate forecast based on technological, organizational and market environments (Shehabuddeen et al., 2006).

Still, according to Muller (2005), the success can be reached if each roadmap fills the following requisites: the topics must be known to all parts involved; clear position over time taking into account the uncertainties in visualization; the main events (likely to happen or even embarrassing) must be presented; and limited quantity of information in order to maintain the review.

Albright and Kappel (2003) support three key successful factors: clear need for the business, the involvement of the right people and the board of director's commitment. It's essential that facilitators with expertise in conducting seminars and generating roadmaps are present preventing waste of time and resources associated to the process of attempt and fail.

Finally, among other factors, in order to organizations achieve success it's necessary that they are apt to identify and validate new opportunities, communicate development plans of new products to the involved parties and establish real time access to products' development plans.

\section{Uses of Roadmapping}

The large number of strategic contexts in which roadmapping applies to makes the approach very flexible. There are many applications for roadmappings, from 
scientific researches of science and technology, forecast to governmental policies or to a specific industrial area, to studies of the evolution of products or technologies. Sometimes the use of roadmapping can be to communicate consumers and suppliers. Roadmaps assist to focus planning processes of a corporation in the future and offer consistent information about the portfolio to help the decision making process.

In summary, technology roadmappings have been used as planning tools, prospection and administration. Recently, its areas of application were extended in the direction of the development process of new products, knowledge management and also virtual innovations. (Lee; Park, 2005).

The technology roadmapping has become one of the key tools in the technological management, for example, in General Motors, organizing the advanced projects portfolios, eliminating duplication of projects, improving the communication and the quality of dialogue in projects. The scenery of growing technology change rate, complex governmental regulations and extreme competitive pressures in the automobile industry, drive General Motors to believe that the technology roadmapping is vital to improve the efficiency and market success (Grossman, 2004).

An important aspect of the strategic planning process consists of gathering and sharing of information in relation to clients and suppliers. Motorola utilizes as planning strategies the so-called collaborative roadmaps gathered in a library. These roadmaps include consumer's needs, suppliers' information, like competitive intelligence, capturing the entire business environment around the corporation's strategies, increasing the potential to communication, data analysis and formulation of more precise business decisions (Richey; Grinnell, 2004).

\section{Panorama of Roadmaps Found in Literature, Highlighting the Ones Related to Chemistry}

The panorama was elaborated from the survey made Robert Phaal (2008), which identified nearly 1300 roadmaps of public domain found on the internet, covering the most varied areas of science, technology and industry, grouping them in study areas.

Based on this document by Phaal (2008) a counting on the mentioned roadmaps was made with the purpose to know the areas in which the technology roadmapping tool was more used. Table I presents the percentage of public domain roadmaps distributed according to its classifications in study areas proposed by Phaal. It's verified that the area that concentrates the largest number of roadmaps is Information and Communications Technology with nearly $23 \%$, in second place the General Industry area with nearly $13 \%$, and in third place there is a tie between Energy Industry and Policy/Government/Community with II\%. Chemistry (in bold) represents only I,5\% of the listed roadmaps.

\begin{tabular}{ccc}
\hline Area & Number of Roadmaps & $\%$ \\
\hline Information and communications technology & 293 & 23,4 \\
\hline Industry - general & 160 & 12,8 \\
\hline Policy/government/community & 142 & 11,4 \\
\hline Industry - energy & 140 & 11,2 \\
\hline Materials & 67 & 5,4 \\
\hline Health care & 64 & 5,1 \\
\hline Life sciences & 59 & 4,7 \\
\hline Industry - electronic & 58 & 4,6 \\
\hline Industry - defence & 44 & 3,5 \\
\hline
\end{tabular}




\begin{tabular}{ccc} 
Earth sciences & 43 & 3,4 \\
\hline Industry - automotive/transport & 42 & 3,4 \\
\hline Aerospace & 39 & 3,1 \\
\hline Physics & 23 & 1,8 \\
\hline Industry - construction & 22 & 1,8 \\
\hline Chemistry (and chemicals process industry) & 19 & 1,5 \\
\hline Astronomy & 16 & 1,3 \\
\hline Industry - manufacturing/operations & 12 & 1,0 \\
\hline General science & 7 & 0,6 \\
\hline TOTAL & 1250 & 100,0 \\
\hline
\end{tabular}

Table I. Roadmaps of public domain selected by Phaal (2008) classified in areas of study, number of roadmaps and its corresponding percentages.

To the survey of roadmaps that refer to subjects belonging to Chemistry, 19 roadmaps mentioned in the document described by Phaal (2008) were assessed and from them the following pieces of information were extracted:

- The vast majority of these roadmaps adopt the text format. Some documents only have text, while others have besides that, representations in bar shapes, multiple layers, tables, flowcharts and/or graphs. For example, the roadmap about the technological forecast of the North American chemical industry for 2020 only utilizes resources of text, while the roadmap directed to catalysis and its technologies utilizes text and the resource of bars to each group (oil / energy, chemical products / polymers / detergents / textiles, fine chemistry / pharmaceuticals / foods) until year 2010 .

- Many authors erroneously name technological prospecting that do not contain structured forecasts of desired goals and do not take into consideration the variable time "technology roadmaps", contradicting Kappel (200I), researcher that emphasized that the roadmap must have the explicit revelation over time to each element presented.

- It's observed that many areas in Chemistry utilize technology roadmaps as tools of technological planning. There can be found roadmaps to, for example, biocatalysts, materials, computational chemistry, chemical processes and environment, with highlight to the area of separation technology.

- Many kinds of organizations perform or order roadmap studies to its areas of interest. Among the kinds of organizations some stand out like companies, universities, research centers, institutes, foundations, industry associations and govern departments.

- Most part of the analyzed roadmaps were performed by one or more organizations in the U.S., making it the country that mostly applies this tool in studies of technological forecast in Chemistry, in second place comes The Netherlands and the U.K.

- Nearly all roadmaps related to Chemistry have forecasts for year 2020, utilizing as a long term deadline a 15 to 20 years interval.

- It's observed that in spite of the existence of technology roadmaps since the 70's, the documents selected were published from 1998, thus, technology roadmapping can be considered a tool of relatively recent use.

In addition, it was observed that in the other study areas classified by Phaal there are other roadmaps that could also be related to Chemistry, since they touch on subjects with the same interface. Some examples are found in 
General Science (laboratories and cleanrooms), Life Sciences (bio-energy and its products, bio-technology, biocatalysis, nanotechnology, agriculture and foods industry), Health Care (sanitization and water treatment, reduction of mercury in sewerage), Earth Sciences (greenhouse gas, carbon sequestration, carbon dioxide capture and storage), Materials (bio/nano-materials, heavy metals, ceramics, aluminum industry, steel industry, concrete, minerals, plastic, rubber, textile, uranium), Energy Industry (nuclear energy, fuel cells, hydrogen, propane, natural gas, electrical power), General Industry (water purification and desalination, water and sewers treatment), Automotive / Transport Industry (fuel cells and hydrogen powered vehicles), Physics (neutron sources), Electronic Industry (semiconductors, coated conductors), Construction Industry (intelligent and sustainable constructions),
Manufacturing / Operations Industry / Operations (welding) and Policy/Government/Community (water sector).

Thus, if we consider the roadmaps of the mentioned areas that relate to Chemistry and the Industry of Chemical Processes, the number of roadmaps that touch on Chemistry subjects go from 19 to 350 . Table 2 shows the number of roadmaps that have interface with Chemistry per study area and its corresponding percentage. In a general way, all roadmaps belonging to Materials and Energy Industry relate to Chemistry. Among the study areas analyzed, the Energy Industry is the most representative (40\%), followed by Materials (nearly $20 \%$ ) and Life Sciences (10\%).

\begin{tabular}{ccc}
\hline Area & Number of Roadmaps & $\%$ \\
\hline Industry - energy & 140 & 40,0 \\
\hline Materials & 67 & 19,1 \\
\hline Life sciences & 34 & 9,7 \\
\hline Chemistry (and chemicals process industry) & 19 & $\mathbf{5 , 4}$ \\
\hline Earth sciences & 16 & 4,6 \\
\hline Industry - general & 15 & 4,3 \\
\hline Industry - electronic & 15 & 4,3 \\
\hline Industry - automotive/transport & 9 & 2,6 \\
\hline Policy/government/community & 7 & 2,0 \\
\hline Industry - construction & 7 & 2,0 \\
\hline Health care & 6 & 1,7 \\
\hline Industry - manufacturing/operations & 6 & 1,7 \\
\hline General science & 5 & 1,4 \\
\hline Physics & 4 & 1,1 \\
\hline TOTAL & 350 & 100,0 \\
\hline
\end{tabular}

Table 2. Roadmaps study areas of public domain classified by Phaal (2008) that hold roadmaps related to Chemistry and the Chemical Process Industry, number of roadmaps of each study area that relate to Chemistry and the Industry of Chemical Processes and its corresponding percentages. 


\section{Conclusions}

- The roadmap created can be understood as a vision that an organization has to reach a specific goal in the necessary time.

- Technology roadmappings can be used to many different applications, among these, to better align, identify deficiencies hard to visualize and choose the best decision to be make.

- The roadmapping has to be understood as a continuous process that is part of the organization's life cycle.

- The main contribution of the technology roadmapping method is the technology roadmapping construction process, not the final document generated (roadmap).

- Among nearly 1300 roadmaps of public domain found on the internet by Robert Phaal (2008), Information and Communications Technology concentrates the largest number (around 23\%), depicting the importance of the correct treatment of the information as competitive advantage in the strategic planning of the organizations.

- $\quad$ Still, related to roadmaps selected by Phaal (2008), it's noticeable that the number of roadmaps belonging to Chemistry (19) is multiplied 18 times if we consider all roadmaps linked to this area, which reflects the great applicability of this tool in the most diversified areas that relate to Chemistry.

\section{References}

ALBRIGHT, R. E. (2007). A unifying architecture for roadmaps frames a value scorecard. Albright Strategy Group.. www.albrightstrategy.com [Accessed 05/03/07]

ALBRIGHT, R. E.; Kappel, T. A. (2003). Roadmapping in the corporation. Research Technology Management, 46, 31 40.

DAIM, T. U.; Oliver, T. (2008). Implementing technology roadmap process in the energy services sector: $A$ case study of a government agency. Technological Forecasting \& Social Change, 75, 687-720.
DRUMMOND, P. H. F. (2005). O planejamento tecnológico de uma empresa de base tecnológica de origem acadêmica por intermédio dos métodos technology roadmapping (TRM), technology stage-gate (TSG) e processo de desenvolvimento de produtos (PDP) tradicional. Dissertation (Master of Science), Federal University of Minas Gerais, Brazil.

GARCIA, M. L., Bray, O. H. (2007). Fundamentals of technology roadmapping. Sandia National Laboratories. Retrieved from the Web 21/04/07. www.sandia.gov/PHMCOE/pdf/Sandia'sFundamentalsofTec h.pdf.

GROSSMAN, D. S. (2004). Putting technology on the road. Research Technology Management, 47, 4I-46.

HINKEBEIN, T. E., Price, M. K. (2005). Progress with the desalination and water purification technologies US roadmap. Desalination, 182, 19-28.

KAPPEL, T. A. (200I). Perspectives on roadmaps: how organizations talk about the future. The Journal of Product Innovation Management, 18, 39-50.

KIM, C., Kim, H., Han, S. H., Kim, C., Kim, M. K., Park, S. H. (2009). Developing a technology roadmap for construction R\&D through interdisciplinary research efforts. Automation in Construction, 18, 330-337.

LEE, S. K., Mogi, G., Kim, J. W. (2009). Energy technology roadmap for the next 10 years: The case of Korea. Energy Policy, 37, 588-596.

LEE, S., Park, Y. (2005). Customization of technology roadmaps according to roadmapping purposes: Overall process and detailed modules. Technological Forecasting \& Social Change, 72, 567-583.

LEE, S.; Yoon, B.; Lee, C.; Park, J. (2009). Business planning based on technological capabilities: Patent analysis for technology-driven roadmapping. Technological Forecasting \& Social Change, doi: 10.1016/j.techfore.2009.01.003.

LI, Y. R. (2009). The technological roadmap of Cisco's business ecosystem. Technovation, 29, 379-386.

MATTOS NETO, P. (2005). Planejamento de novos produtos por intermédio do método technology roadmapping (TRM) em uma empresa de base tecnológica do setor de internet móvel. 
Dissertation (Master of Science) - Production Engineering, Federal University of Minas Gerais, Brazil.

MULLER, G. (2005). Roadmapping. Embedded Systems Institute, jul. 2005. www.gaudisite.nl [Accessed 0/I0/09]

PETRICK, I. J. Echols, A. E. (2004). Technology roadmapping in review: $A$ tool for making sustainable new product development decisions. Technological Forecasting \& Social Change, 7I, 8I-100.

PHAAL, R. (2008). Public domain roadmaps. University of Cambridge, jun. 2008. http://www.ifm.eng.cam.ac.uk/ctm/ trm/documents/published_roadmaps.pdf. [Accessed 20/0I/10]

PHAAL, R., Farrukh, C. J. P., Probert, D. R. (2004). Technology roadmapping - A planning framework for evolution and revolution. Technological Forecasting \& Social Change, 7I, 5-26.

PHAAL, R., Farrukh, C. J. P., Probert, D. R. (200I). T-Plan: The fast start to technology roadmapping - Planning your route to success. Cambridge University, Institute of Manufacturing, UK.

RICHEY, J. M., Grinnell, M. (2004). Evolution of roadmapping at Motorola. Research Technology Management, 47, 37-4I.

RINNE, M. (2004). Technology roadmaps: Infrastructure for innovation. Technological Forecasting \& Social Change, 7I, 67-80.

SHEHABUDDEEN, N., Probert, D., Phaal, R. (2006). From theory to practice: Challenges in operationalising a technology selection framework. Technovation, 26, 324-335.

SUH, J. H., Park, S. C. (2009). Service-oriented technology roadmap (SoTRM) using patent map for R\&D strategy of service industry. Expert Systems with Applications, 36, 67546772. 